\title{
DESMITIFICANDO OS VALORES DA MATERNIDADE EM ELISA LISPECTOR'
}

\author{
DEMITIFYING THE VALUES OF MOTHERHOOD \\ IN THE FICTION OF ELISA LISPECTOR
}

\section{Patrícia Lopes da Silva²}

RESUMO: O presente trabalho propõe discutir a subversão da maternidade no livro O Muro de pedras, de Elisa Lispector, publicado em 1963. Nesse romance, por meio da protagonista Marta, a autora problematiza a condição feminina e a maternidade, apresentando uma mulher que demonstra sentir um grande vazio existencial e uma certa incredulidade na vida que pode ser percebido por meio do sentimento de tristeza e de solidão presentes na narrativa, que a arrasta para um possível sentimento de desajuste diante do mundo. Para essa investigação, recorreremos à algumas reflexões presente na Crítica Literária que analisam os valores da maternidade como em Elisabeth Badinter, a qual amplia o debate sobre o papel da mulher na criação dos filhos, desmistificando as convenções criadas na sociedade. Também investigamos teorias que discutem a condição feminina e a representação da mulher na contemporaneidade, como o caso de Nádia Batella Gotlib e Mary Del Priore, dentre outras temáticas que auxiliarão na análise do objeto aqui investigado. Com isso, reinserimos Elisa Lispector no cenário literário brasileiro, almejando um olhar ressignificador acerca de sua escrita. PALAVRAS-CHAVES: Feminino. Maternidade. Elisa Lispector.

ABSTRACT: This paper proposes to discuss the subversion of motherhood in the book O Muro de Pedras, by Elisa Lispector, published in 1963. In this novel, through the protagonist Marta, the author problematizes the female condition and motherhood, presenting a woman who demonstrates feeling a great existential emptiness and a certain unbelief in life that can be perceived through the feeling of sadness and loneliness present in the narrative, which drags it towards a possible feeling of misfit before the world. For this investigation, we will resort to some reflections present in Literary Criticism that analyze the values of motherhood as in Elisabeth Badinter, which broadens the debate about the role of women in raising children, demystifying the conventions created in society. We also investigated theories that discuss the female condition and the representation of women in contemporary times, such as the case of Nádia Batella Gotlib and Mary Del Priore, among other themes that will assist in the analysis of the object investigated here. With that, we reinserted Elisa Lispector in the Brazilian literary scene, aiming at a resignificant look about her writing.

KEYWORDS: Female. Maternity. Elisa Lispector.

\footnotetext{
${ }^{1}$ Artigo recebido para avaliação em 15/08/2020 e aceito para publicação em 15/10/2020.

${ }^{2}$ Doutora em Estudos Literários pela Universidade Federal de Uberlândia (UFU). Atualmente integra o corpo docente da Universidade Estadual de Montes Claros - Unimontes. E-mail pattyeloren@ hotmail.com - https://orcid.org/0000-0001-5421-7238.
}

Interdisciplinar, Săo Cristóvăo, UFS, v. 34, jul-dez, p. 189-206, 2020

D0I: https://doi.org/10.47250/intrell.v34il.14976| 189 


\section{Introduçằ ${ }^{3}$}

\section{Redescobrindo Elisa Lispector}

Passados setenta e quatro anos (1945-2020) da publicação do primeiro livro, muitos estudos ainda precisam ser descobertos a despeito da produção literária de Elisa Lispector e consequentemente sobre a própria escritora, pois, embora sua produção seja relevante e forte no que diz respeito aos textos que produziu, a autora ainda é pouco conhecida no meio literário.

Com um estilo próprio, a autora traça um perfil poético e existencialista em seus escritos, capaz de levar o leitor a refletir sobre a questão da mulher na sociedade e sobre a existência humana, temas que impulsionam as mulheres a saírem do clichê social e mostrarem suas inquietações pessoais, reinventando a busca de si mesmas e a fonte de seus equilíbrios; vivendo dilemas e insatisfações; redescobrindo-se cada vez mais através do trânsito e de seus múltiplos movimentos, mas que, ao mesmo tempo, as mantem envolvidas em tristeza e melancolia.

A autora tem uma bibliografia de grande relevância para os estudos de literatura nacional. Publicou romances e livros de contos que ainda são pouco conhecidos pelo público leitor.

Elisa Lispector cursou Sociologia na Faculdade Nacional de Filosofia e também Crítica de Arte na Faculdade Brasileira de Teatro. Durante três décadas, a partir de 1940, atuou na imprensa, colaborando em revistas como a Fon-Fon, bem como em jornais como o Diário de Notícias e O Jornal. Ganhou os prêmios José Lins do Rego, da Livraria José Olympio Editora, em 1962, e o Coelho Neto, da Academia Brasileira de Letras, em 1964. Foi funcionária do Ministério do Trabalho até 1969, quando se aposentou.

Na dissertação de mestrado intitulada Elisa Lispector - registros de um encontro (2015), Jeferson Alves Masson faz uma importante reflexão sobre a obra da autora. Segundo Masson, nos romances de Lispector há traços (auto) biográficos. A pesquisa realizada foi de cunho pessoal, no qual o autor relata seu amor pela escrita elisiana e também faz uma associação entre a ficção e vida de Elisa Lispector. ${ }^{3}$ Este artigo é um recorte da minha Tese de Doutorado intitulada "Exílio e deslocamento feminino: a
literatura nômade de Elisa Lispector", vinculada ao programa de pós-graduação em Estudos Literá-
rios, defendida em setembro de 2020 na Universidade Federal de Uberlândia - UFU. A Tese já se en-
contra disponível para pesquisa e download no site do repositório de Teses da referida Universidade.

Interdisciplinar, Săo Cristóvăo, UFS, v. 34, jul-dez, p. 189-206, 2020 D0I: https://doi.org/10.47250/intrell.v34il.14976| 190 
Fernanda Cristina de Campos, em sua dissertação, $\mathrm{O}$ discurso melancólico em Corpo a corpo, de Elisa Lispector (2006), também se dedicou à ficção da escritora. Essa leitura merece destaque, inicialmente, por fugir da análise de temáticas como memória, exílio, religião e por enfatizar o romance Corpo a corpo, de 1983. A pesquisadora fez um percurso sobre o cânone desconhecido, apresentando na obra de Elisa Lispector pontos de aproximação entre romances e contos. Também há um artigo de Joyce Kelly Barros Henrique, publicado nos Anais do VI ENLIJE (2016), o qual teve como objetivo analisar a perspectiva narrativa no conto Amor, da coletânea $O$ tigre de bengala. De acordo com Henrique, o conto de Lispector tem um caráter introspectivo, apresentando conflitos, angústias e desenganos da protagonista, apesar de se valer de um narrador em terceira pessoa.

Berta Waldman no texto Clarice e Elisa Lispector: caminhos divergentes (2014) procurou abordar em seus estudos a questão judaica no texto elisiano, principalmente em No exílio, e como essa questão está diluída na obra de Clarice Lispector:

Nádia Batella Gotlib, em Por uma nova história das mulheres escritoras no Brasil: algumas anotações em torno das irmãs Lispector (2013), inicialmente faz um relato do mercado editorial, o valor da qualidade de textos, a existência de boa crítica e os interesses mercadológicos do livro para problematizar os diferentes destinos literários das irmãs Lispector. Para a estudiosa, Elisa Lispector é como uma arquivista da família, pois o passado é rememorado como enfrentamento militante; seus escritos são de memória e têm cunho autobiográfico.

Gotlib (2013) analisa No exílio. Segundo ela, há três edições brasileiras e uma francesa do livro, no qual são criados personagens muito parecidos com a família Lispector, trazendo coincidência de nomes. São narrados detalhes do sofrimento passado, a perseguição dos judeus na Ucrânia; aponta também as dificuldades do acesso à educação formal, rituais religiosos, o amor à leitura e à cultura. Parte dessa história é recontada em Retratos antigos. Nessa obra, a voz da Elisa narradora (nessa obra a autora se identifica como narradora), compondo um relato e fotos de pessoas identificadas como membros da família são apresentadas ao leitor e se tornam importantes no conjunto da obra, pois esse leitor passa a acreditar que de fato conhece toda a família Lispector.

Interdisciplinar, Săo Cristóvăo, UFS, v. 34, jul-dez, p. 189-206, 2020 D0I: https://doi.org/10.47250/intrell.v34i1.14976| 191 
O livro $O$ muro de pedras é narrado em terceira pessoa a protagonista é Marta, filha única de um casal. O pai, cujo nome não é citado, aparece na figura de alguém que está acamado em um sanatório, tentando se recuperar de uma doença (que também não é identificada na obra) e permanece neste local até sua morte. A mãe, Eunice, sempre muito ocupada com afazeres de casa e com a costura, fazendo com que ambas se distanciem, nascendo um sentimento contraditório de amor e ódio entre ambas. A partir desse embate, Marta - protagonista da narrativa - passa a sentir-se sozinha e solitária, impedida de ter paz consigo mesma. Distanciaram-se cada vez mais, como que criando uma espécie de muro entre elas.

A narradora apresenta o estado melancólico da protagonista através do espaço e da natureza, olhando as gotículas de chuva caindo sobre as agulhas dos pinheiros, observando a água escorrendo pelas valas, assemelhando aos minúsculos rios, os ventos, as árvores. A natureza ocupa um lugar privilegiado nessas pequenas imagens discriminadas; é como refúgio feminino: o mar, os pássaros e as plantas.

Elisa escreve sob nuances fortemente marcadas pelos elementos água, terra, fogo, ar, imagens poéticas que dão lirismo à narração, possibilitando a materialização humana. De forma em forma, a autora apresenta também outras questões importantes nesse romance, como a maternidade e o casamento. Na vida adulta, ela casa-se com Heitor, mas diante da vida interior conflituosa, com dificuldade de se relacionar com as pessoas, separa-se dele.

Com o passar do tempo, Marta passou a sentir uma solidão inviolável; se viu aparentemente sem saída, sofreu com uma doença não identificada, provavelmente causada pelos desequilíbrios emocionais e mentais, proveniente das angústias que não são curadas com remédios. Foi ainda acometida por uma febre que, aos poucos a deixou enfraquecida. Mas irônico pensar que doença lhe dava uma espécie de conforto. Para tentar sair desse estado de solidão profunda, Marta, recorre a maternidade, pensando em desprender daí um novo sentido a sua vida.

Interdisciplinar, Săo Cristóvăo, UFS, v. 34, jul-dez, p. 189-206, 2020 D0I: https://doi.org/10.47250/intrell.v34il.14976 192 


\section{Uma discussăo teórica acerca da maternidade}

A maternidade quase sempre está associada ao amor, ao cuidado com o filho, alicerçada e amparada na paternidade. $\mathrm{Na}$ tradição cristã, a virgem Maria, representa a mãe ideal, cheia de graça, pura e imaculada e José, o cuidador, que deu suporte na cooperação da missão de Maria e na educação do filho Jesus Cristo (homem). Essa concepção de família alicerçado nos preceitos do Cristianismo é considerada como uma base fundamental na formação da humanidade.

$\mathrm{Na}$ contemporaneidade, ainda é muito comum encontrar uma leitura de modelo ideal de maternidade. Um papel parece gratificante para a mulher, independente da história que essa tenha vivido para chegar à concretização da maternidade. A mãe usualmente é considerada uma santa, imaculada, cuja vida se resume a renúncia de seus próprios desejos em função dos filhos; cabe à mulher a responsabilidade de zelar pela saúde da família e pelo desenvolvimento emocional dos filhos (e do marido), deve-se mostrar paciente, dedicada ao lar e a tudo que envolve esse contexto familiar.

Elisabeth Badinter, no livro intitulado Um amor conquistado: o mito do amor materno (1985) faz uma reflexão sobre a condição da mulher na contemporaneidade. Sua análise se debruça sobre o papel das mulheres na sociedade francesa, contudo, partindo de uma apropriação de suas reflexões e discussões para aquela realidade, torna-se possível expandir a problematização da condição feminina em outros contextos, como no caso da representação da mulher através da personagem Marta, de Elisa Lispector. Badinter (1985) desmistifica o instinto da maternidade, a origem do amor materno, desconstruindo o discurso de que a mulher nasce para ser mãe. A autora afirma ainda que, "embora muitos cientistas saibam perfeitamente que o conceito de instinto está caduco, alguma coisa em nós, mais forte do que a razão, continua a pensar na maternidade em termos de instinto" (BADINTER, 1985, p. 16). Segundo ela, a mulher é um "ser histórico", dotado da capacidade de simbolizar, e cujo desejo é particular.

Para Badinter, a publicação de Émile, de Rossueau, em 1762 é responsável por exercer influência no comportamento feminino que atribuiu algumas instruções para que as mulheres não se sacrificassem ao ser tornarem mães. A partir do avanço

Interdisciplinar, Săo Cristóvăo, UFS, v. 34, jul-dez, p. 189-206, 2020 D0I: https://doi.org/10.47250/intrell.v34i1.14976|193 
da psicanálise, houve uma tendência de se responsabilizar a mãe pelas dificuldades e problemas que surgiam nos filhos e filhas. Várias investigações culminavam em problemas emocionais que convergiam para a relação dos pacientes com suas mães. A figura da mãe, então, passou a ser responsabilizada pelo cuidado com a saúde mental e emocional das crianças.

Freud (ano) destacou a importância da relação mãe/filho, acentuando a imagem de devoção e sacrifício que caracterizava a boa progenitora, com isso, essa mãe se tornou a figura centralizadora da família e sua atuação positiva ou negativa, implicaria no sucesso ou nas decepções que essa família experimentaria ao longo do tempo. De certa forma, toda exceção a essa norma era considerada anormal por excelência.

A partir de então, a educação materna tinha como finalidade educar as meninas para desempenhar bem as funções atribuídas ao sexo feminino: ser boa esposa, saber costurar, ter noções de higiene, dentre outras funções relacionadas ao bem estar da casa e da família, restringindo-as, apenas, ao espaço doméstico. Essa concepção estava de acordo com valores dominantes da sociedade patriarcal, que só começaram a ser questionados a partir da década de 1960 , com os movimentos feministas que lutaram pela igualdade e pelo fim dos privilégios dos homens em relação ao saber e o poder.

O século $X X$ foi marcado pela possibilidade de as mulheres ingressarem no mercado de trabalho, desse modo, a maternidade e a vida doméstica começaram a perder espaço e as novas escoIhas tiveram como reforço, por exemplo, a opção da mulher por não ser mãe. Foram diversas mudanças, tanto no âmbito social, quanto no cultural e tecnológico. As ideias feministas foram difundidas, compondo várias vertentes, entre elas, as radicais, as marxistas, dentre outras. Há ainda uma discussão sobre a questão da igualdade na diferença, ou melhor, a mulher como equivalente ao homem. Após a década de noventa, começou a se falar em pós-feminismo.

Uma outra reflexão que merece destaque foi o conceito de gênero e sexo, proveniente dos debates feministas. Para alguns estudiosos, existe uma singular distinção entre o sexo biológico e a identidade adquirida pelo sujeito. Para Teresa de Lauretis "o sujeito é constituído, no gênero, mas não apenas pela diferença

Interdisciplinar, Săo Cristóvăo, UFS, v. 34, jul-dez, p. 189-206, 2020 D0I: https://doi.org/10.47250/intrell.v34i1.14976 194 
sexual, mas por meio de códigos linguísticos e as representações culturais" (LAURETIS, 1994, p.208). O sujeito é caracterizado na sociedade pelos papéis sociais e suas diferenças. Ser homem ou mulher está ligado à constituição social, podendo variar conforme a cultura de um determinado lugar.

\section{Às avessas: entre a maternidade e o sentido feminino}

O livro intitulado $O$ muro de pedras, escrito por Elisa Lispector, foi publicado na década de 1960, época em que prevalecia o papel conservador das mulheres, que tinham a obrigação principal, o casamento e concepção de filhos. Nesse romance, por meio da protagonista Marta, Elisa Lispector problematiza a condição feminina e a maternidade apresentando uma mulher que sente um grande vazio existencial, bem como, incredulidade na vida, por meio do sentimento de tristeza e de solidão experimentado ao longo da narrativa. Essa personagem apresenta uma vida interior muito conflituosa, com dificuldade de se relacionar com as pessoas, sentindo-se desajustada diante do mundo e fazendo diversos tipos de reflexões sobre a sua própria condição de existência.

$\mathrm{Na}$ época em que foi lançado, o livro recebeu muitas críticas positivas. Pietro Ferrua, em Indagações metafísicas na obra de Elisa Lispector (1978) afirma que a autora fugiu de qualquer tentação folclórica ou colorista, afastando-se da visão de araras e mulatos, sobrados e mocambos, cangaceiros sertanejos e pescadores baianos, garotos da calçada e garotas Ipanema que tinha alimentado a literatura brasileira até aquela época. Elisa Lispector, segundo ele, para construir uma introspecção, recorreu a uma linguagem depurada de qualquer coloquialismo, sem fixá-la no tempo e no espaço ou ligá-la a uma sociedade de determinado momento histórico.

Homero Senna (s/p), na orelha do livro, afirma que no texto da escritora há densidade psicológica e duas outras qualidades que não poderia faltar em um romance: estrutura e linguagem. Elisa demonstrava ser alguém com o pleno domínio do gênero, o estilo, sem ser rebuscado, se configura justo e expressivo, com indisfarçável ar de novidade.

Como já foi destacado, a narrativa tem como protagonista a personagem Marta, filha única, a qual teve uma vida conflituo-

Interdisciplinar, Săo Cristóvăo, UFS, v. 34, jul-dez, p. 189-206, 2020 D0I: https://doi.org/10.47250/intrell.v34il.14976| 195 
sa com os pais durante toda a sua infância. O nome do pai não é citado; há, no texto, uma referência de paternidade, relacionada a um homem ausente, haja vista que ficou em um sanatório durante muito tempo antes de sua morte. A mãe, Eunice, aparece no texto, contudo, a narrativa destaca que esta não dava a atenção necessária para a filha, uma vez que estava sempre ocupada com os afazeres domésticos e com a máquina de costura. Com esse histórico familiar, Marta foi crescendo triste e sozinha e o sentimento de indiferença foi aumentando com o decorrer dos anos. As lembranças de infância sempre voltam à tona na personagem, causando-lhe raiva: "se reviu na loja de calçados com a mãe, e, ante a sua recusa do modelo por ela escolhido, e a manifestação de sua preferência, a mãe exclamar com sarcasmo: 'Vaidozinha, hein?" " (LISPECTOR, 1976, p. 21). A dor, o espanto e a raiva daquele momento despertavam uma profunda frustração, pois ela não poderia aceitar as atitudes da mãe, mesmo que a amasse.

Ao chegar à vida adulta, Marta tentava compreender o distanciamento ao qual se encontrava. A mãe Eunice vai morar em outra cidade, abandonando a filha. Mesmo com a viagem da mãe, Marta continuou com a visão angustiante da vida. A impressão que se tem, a partir da leitura da narrativa, é de que não havia nenhuma importância na relação mãe/filha. Na despedida entre elas, a protagonista se destaca em cena, observando o navio desaparecer: "Em pouco sua silhueta se foi apagando, confundindo-se com as manchas de cor dos vultos de outros viajantes, depois já não se vendo senão o bojo do navio até que também este começou a diminuir, à medida que acelerava a marcha em demanda à barra" (LISPECTOR, 1976, p.01).

Ao ver o navio sumindo no horizonte, Marta sente-se angustiada. Em seus pensamentos ela conjectura que, agora, separadas física e emocionalmente pelo oceano, perderiam todo e qualquer vínculo que as unia. A partida da mãe significava, naquele momento também, uma certa morte para ela, não física, mas como uma quebra de laços afetivos, embora ínfimos. A imagem do desaparecimento do navio também implicaria a entrada de Marta em outro universo de solidão: "estava esgotada, depois de um longo esforço de aparentar coragem e não dar para perceber até que ponto a partida da mãe lhe doía tanto" (LISPECTOR, 1976, p. 02).

Interdisciplinar, Săo Cristóvăo, UFS, v. 34, jul-dez, p. 189-206, 2020 D0I: https://doi.org/10.47250/intrell.v34i1.14976| 196 
Com o passar do tempo foi aperfeiçoando seu conhecimento de mundo, até poder se chamar de moça evoluída. Segundo a narradora, os tempos mudaram, os jornais falavam em guerras, os homens em greve, as mulheres em emancipação. Mesmo vivendo em seu tempo, Marta, tentava adaptar-se ao mundo feminino, "embelezando-se", "apesar de ser canhestra", "desajeitada e indecisa". Observava as pessoas ao seu redor, admirava a atitude dessas pessoas ao saber lidar com seus próprios desejos e vontades, muito diferente da sua conduta individual. Enquanto refletia, a protagonista reconhecia a superioridade no julgamento prático da mãe.

Na busca de reafirma-se no mundo e superar a solidão, casa-se com Heitor, que a acolheu. Com o passar do tempo: "após casados, ele entrava em casa e saía, sempre gentil, delicado, indiferente - indiferença total quanto ao que ela fazia com o seu tempo, seu dinheiro, sua vida" (LISPECTOR, 1976, p. 33). Segundo Ferrua (1979), o amor está presente em $O$ muro de pedras, entretanto, a incomunicabilidade dos seres, mesmo ao interior do casal, demostra, de certa forma, como o amor, algumas vezes, se torna impotente ou insuficiente para estabelecer uma completa comunhão entre os seres envolvidos.

Mary Del Priore, em Pequena história de amor conjugal no Ocidente Moderno (2007), afirma que o casamento é uma instituição básica para a transmissão de patrimônio. Desde meados do século XVI, a igreja católica tinha dois propósitos para o casamento: reafirmá-lo como sacramento, uma vez que protestantes, como Lutero, julgava-o como necessidade física, e convertê-lo a uma instituição básica, eliminando os ritos tradicionais. Não era um assunto relacionado ao sentimento, pois havia um risco de desestabilização financeira, tratava-se de uma negociação financeira conservando as fortunas das famílias. Durante muito tempo, poucos esforços foram feitos para estimular relações entre amor e casamento. Del Priore (2007) afirma que, a partir do século XVIII, a sociedade começou a mudar sua concepção em relação ao casamento, e, lentamente, os casais passaram a vivenciar o amor como amantes e o erotismo extraconjugal entrou, desviando a reserva tradicional.

Heitor e Marta eram indiferentes um ao outro; diante de tal situação, ela continuou a levantar os muros de sua fortaleza:

Interdisciplinar, Săo Cristóvầo, UFS, v. 34, jul-dez, p. 189-206, 2020

D0I: https://doi.org/10.47250/intrell.v34i1.14976|197 
"estava emparedada dentro de seu sofrimento como um morto dentro de seu túmulo" (LISPECTOR, 1976, p. 33). Vivia um sofrimento que criara para si mesma, incapaz de reagir ou de lutar; era como se estivesse morta em vida. Apesar de amá-lo não se sentia feliz ao lado dele, não tinha desejos carnais, conviviam na mesma casa como estranhos, e isso levou o casamento ao fracasso. Heitor, então, conforme pode ser constatado na narrativa, reuniu suas roupas, jogou-as em uma maleta e partiu.

Ainda sem conseguir se recuperar da separação, Marta conhece Maurício em uma festa. O rapaz trouxe-lhe uma nova carga de sensações, virilidade, expectativas de uma vida sem frustrações; talvez o resgate do sentido da vida. Os dois se envolveram em um relacionamento amoroso. A diferença de idade fez com que mantivessem o envolvimento em segredo. Para ele, relacionar-se com uma mulher mais velha seria ter mais experiência, amadurecimento pessoal. Sobre esse assunto Ferrua, afirma que:

Essa sensualidade muito contida deixa apenas transparecer o vigor das sensações e dos sentimentos das personagens lispectorianas. Escolhendo um estilo de grande elegância e alusividade, a autora pinta quadros a maneira de De Chirico ou Morandi, onde a profunda tensão emocional e dissimulada por tris de uma aparecia de algidez (FERRUA, 1979, p. 417).

É válido lembrar que as pinturas de Chirico e Morandi são consideradas pinturas metafísicas, as quais apresentam figuras emblemáticas como: sombras sedutoras, objetos imprevistos e inquietantes. Os pintores, em grande parte de suas obras artísticas, criam uma realidade para além do mundo sensível, com ambiente enigmático e misterioso. Essa alusão feita por Ferrua (1979), corrobora com o estado de espírito angustiante e solitário em que a protagonista se encontrava.

Porém, Marta não contava que naquele jogo excitante de sedução havia algumas dificuldades, principalmente porque Maurício "não precisava dela, movia-se independente dela, e quando chegava, não era para sua casa que ele vinha, nem para a sua existência a dois, mas simplesmente para um encontro" (LISPECTOR, 1976, p. 91). O sentimento de abandono se abatia, e agora não se tratava de um sentimento de solidão, mas de um vazio. Ela voltou a sua solidão ascética e preferiu acabar com a sua convivência com

Interdisciplinar, Săo Cristóvầo, UFS, v. 34, jul-dez, p. 189-206, 2020 D0I: https://doi.org/10.47250/intrell.v34i1.14976| 198 
ele. "Quando Maurício veio, sua presença não mais teve o poder de perturbá-la, de arrastá-la para fora de si. Ele ficou intrigado, e estranhamente também silenciou" (LISPECTOR, 1976, p. 100).

Sentindo-se melancólica e em uma tentativa de salvar-se, Marta exila-se em Granja Quieta, uma chácara que herdara do pai. Precisava "recomeçar de novo, os elos partidos, um não emendando os outros" (LISPECTOR, 1976, p. 105). Ao chegar no local, não se interessou com a administração em nem com os afazeres da casa. Pensava quase que exclusivamente em uma vida renovada, cheia de esperança; buscava a felicidade a qualquer custo. Porém, com o passar dos anos, mergulhava novamente em um universo apático, sem perspectiva, e mais uma vez, o encontro com a solidão podia ser percebido. Ela construiu uma cabana no bosque, sob o pretexto de distanciar-se de todos, a fim de refugiar-se. Algumas vezes olhava para o espelho e se via tão frágil e translúcida que parecia sentir medo de que a doença do pai tivera deixado raízes. Então, tomava xaropes, injeções e ficava em repouso, evitando a morte. Em seus passeios matinais pelos recantos do sítio, contemplava de longe, Bruno, totalmente absorvido e centrado em sua tarefa, de corpo flexível e musculoso. Também não passava despercebido o jeito do homem fitá-la com aqueles olhos escuros. Em uma troca de olhares, um pensamento ocorreu-Ihe: Um filho. Ele poderia dar-Ihe o que ela precisava para renascer, estancar a angústia e encontrar a paz.

Marta criou um momento propício para se entregar sexualmente a Bruno. Percebeu naquele contexto a liberdade que um dia a mãe lhe deu com sua partida, que em seguida ficou reforçado na indiferença de Heitor, e, finalmente concretizado na rejeição de Maurício; todas essas coisas conferia-lhe um poder para efetivar aquele pensamento que lhe acometeu.

A postura adquirida pela protagonista demonstrou uma mulher totalmente liberta de julgamentos; em sua decisão, optou por buscar aquilo que desejou. O corpo nesse momento passa a ter poder, ela adquire um novo posicionamento diante da vida, não se sentiu censurada, apesar da idade, nem da possibilidade de gerar um filho sem o consentimento do pai. Apenas demonstrava segurança e firmeza para aquele momento, pois queria estar bem consigo mesma; cuidar de uma criança poderia, enfim, preencher o vazio de sua existência.

Interdisciplinar, Săo Cristóvăo, UFS, v. 34, jul-dez, p. 189-206, 2020 D0I: https://doi.org/10.47250/intrell.v34i1.14976| 199 
Nesse contexto, torna-se relevante pensar nas discussões propostas por Elisabeth Badinter (1985) acerca do desdobramento feminino. Para a autora, ainda existe uma excessiva tendência de se confundir determinismo social e biológico. Desse modo, apesar de muitas discussões sugerirem que os comportamentos são socioculturais, na cultura ocidental, a mulher sempre foi (e continua sendo) vista como um ser biológico, mais especificamente por sua capacidade de gerar filhos. Entretanto, atualmente, os questionamentos vêm sendo feitos por vários estudiosos a respeito desta questão, principalmente no tange as noções que configuram o instinto materno. Ainda segundo a autora:

\footnotetext{
Os valores de uma sociedade são por vezes tão imperiosos que têm um peso incalculável sobre os nossos desejos. [...] O desejo de ter um filho é complexo, difícil de precisar e de isolar de toda uma rede de fatores psicológicos e sociais. À ideia de "natureza feminina", que cada vez consigo ver menos, prefiro a de uma multiplicidade de experiências femininas, todas diferentes, embora mais ou menos submetidas aos valores sociais cuja força cálculo. A diferença entre a fêmea e a mulher reside exatamente nesse "mais ou menos" de sujeição aos determinismos (BADINTER, 1985, p. 15).
}

Como é possível observar na citação acima, os valores construídos de uma sociedade destinados ao perfil feminino são relacionados a uma esfera específica, tal como o casamento, a maternidade, a sedução feminina, a família, entre outros. Entretanto, o desejo de ser mãe é complexo, está intrínseco em fatores psicológicos e sociais; o amor materno pode ser frágil, sendo assim, a mulher tem total liberdade em optar pela maternidade ou não.

Com o nascimento do filho, Marta volta para a casa grande e "teve a sensação de possuir a sua própria vida em suas mãos" (LISPECTOR, 1976, p. 138), comovia-se com o agitar dos bracinhos e das pernas; via o filho com deslumbramento e beleza, deleitando-se nas pequenas alegrias, abrindo-se ao conhecimento intuitivo; ela que nunca soubera o que fazer nos seus dias, passou a possuir a sabedoria intuitiva e milenar da primeira fêmea a proteger sua cria. Percebe-se que a maternidade, a princípio, foi lhe preenchendo o cotidiano com alegria, consolando seu próprio

Interdisciplinar, Săo Cristóvăo, UFS, v. 34, jul-dez, p. 189-206, 2020 D0I: https://doi.org/10.47250/intrell.v34i1.14976|200 
destino. A maternidade, nesse primeiro momento, é encarada de forma acolhedora e sensível, sem a necessidade da rendição por intermédio das "amarras" do matrimônio. E ainda, a protagonista tinha uma convivência cotidiana pacífica com Bruno, o pai que decididamente ela escolheu para seu filho.

Com o passar dos anos, o filho foi crescendo e Marta novamente se vê imersa na solidão:

(...) se entristecia um pouco. Seu filho estava crescendo(...) parecia precisar cada vez menos dela, cada vez mais absorvido pela beleza do mundo, pela grandeza do mundo, então ela entrava em casa, caminhando pausadamente, indagando consigo sobre o sentido daquilo que estava vivendo (LISPECTOR, 1976, p.149).

Ela sente-se fatigada pela mesmice do sítio, melancólica e com a vida angustiante de outrora, em uma eterna insatisfação de viver: "na cidade quisera a quietude do campo; no campo - o que era mesmo que desejava agora?" (LISPECTOR,1976, p.143). Deparou-se com uma falsa sensação de quietude durante o tempo em que o filho era criança. Esse período de infância e mistificado para algumas mulheres, época em que há uma dependência física, a beleza das primeiras experiências como falar, andar e descobrir o mundo. A mãe permanece nos cuidados com a cria, perdendo sua individualidade e identidade, toda a sua vida afetiva está ligada a maternidade.

Maria Elisa Pessoa Labaki, em seu artigo Ter filhos é o mesmo que ser mãe? (2008) discute a diferença entre ser mãe e ter um filho. De acordo com Labaki, não há continuidade entre a gravidez e a maternidade, mas uma ruptura que se opera no nascimento do bebê. Implica, para a mulher, uma mudança de um para o outro. A maternidade estaria no registro da separação e da perda, e não do ganho, o ato de se ter um filho está associado ao termo "ganhar o bebê", porém, para ser mãe deve-se perder as ilusões narcísicas.

A espera de um filho, durante a gravidez, bem como o investimento de desejo no filho que será adotado, deveria dotar a mãe com esta capacidade de perda da imagem ideal do bebê, sem a qual a criança não se subjetivaria. Não havendo subjetivação, tornar-se-ia,

Interdisciplinar, Săo Cristóvăo, UFS, v. 34, jul-dez, p. 189-206, 2020 D0I: https://doi.org/10.47250/intrell.v34i1.14976|201 
na melhor das hipóteses, um simulacro da psicopatologia materna. Assim, mãe devotada é aquela que se esquece e deixa nascer um projeto de alteridade (LABAKI, 2008, p.282).

As atitudes de Marta corroboram com o que Labaki (2008) descreveu acerca de uma mãe ter um filho, pois, de acordo com a narrativa, pouco laço emocional foi criado depois do nascimento da criança, e, à medida em que o filho vai crescendo, há uma visível perda desse vínculo, desmontando o sistema de regras e modelos pré-estabelecidos sobre o amor materno, desmitificando tanto os valores de mulher concebidos pela sociedade quanto a imagem "imaculada" da maternidade.

Ainda segundo a autora, a descendência é uma das poderosas formas das pessoas buscarem satisfazer seu narcisismo frustrado infantil, entretanto, a maternidade solicita um esforço contrário, exigindo desprendimento de si e total entrega ao outro. Isto é, de separação de um ideal projetado no bebê que reflete as ilusões narcisistas da mãe e suas representações de filha ideal. A gravidez mantém uma ligação entre mãe e filho através do corpo para dois, o parto faz a ruptura. Com o nascimento, mãe e filho, precisam ser solícitos à diferença. A personagem ancorou-se em um relacionamento adverso, mesmo vinculado a outra pessoa, volta a se sentir insegura e solitária, uma vez que a maternidade não solidificou a afetividade.

É válido salientar que a protagonista tinha uma relação conturbada com a mãe. Desde criança, vivia um misto de sentimentos que abarcava a raiva e a pena simultaneamente, fazendo com que ela sofresse cada vez mais com um trauma marcado pela angústia e pela perda do amor da mãe. O psicanalista francês André Green, no livro Narcisismo de vida, narcisismo de morte (1980), a partir dos estudos de Freud, Melanie Klein e Winnicott, cria uma série de discussões sobre o complexo da mãe morta, o qual remete ao narcisismo primário, não se referindo a morte física, mas uma condição de ausência materna. A mãe morta psiquicamente aos olhos da criança, em consequência de uma depressão que ela própria atravessa diante da perda de um ente querido, conflitos familiares, decepção, abandono, humilhações: "em todos os casos, a tristeza da mãe e a diminuição do interesse pela criança estão em primeiro plano" (GREEN, 1980, p. 247).

Interdisciplinar, Săo Cristóvăo, UFS, v. 34, jul-dez, p. 189-206, 2020 D0I: https://doi.org/10.47250/intrell.v34il.14976| 202 
Há um desinvestimento por parte do objeto (mãe) causando uma distância afetiva e um certo abandono, esses percalços parecem causar na criança uma ferida narcísica, sendo interpretada pela mesma como a perda do amor, os prejuízos posteriores são catastróficos, relaciona-se com um vínculo inconsciente com o objeto perdido, tal qual como acontece com o sujeito melancólico. Essa problemática narcísica demonstra "as exigências do Ideal, do Eu consideráveis, em sinergia ou em oposição com o Supereu" (GREEN, 1980, p. 246), provocando, no sujeito, uma sensação de impotência, de incapacidade de sair do conflito, de posicionar-se diante da vida, de manter e sustentar os relacionamentos, de obter a realização pessoal ou profissional. Quando isso acontece, sobrevém uma "insatisfação profunda frente ao resultado" (GREEN, 1980, p. 246).

Há uma semelhança do complexo de mãe morta na relação estabelecida entre Marta e sua mãe. Não é a morte real de Eunice que causa transtorno emocional da personagem, mas sim, a ausência afetiva e o distanciamento físico posterior, deixando marcas profundas de dor, angústia e melancolia. A protagonista tentou encontrar conforto na maternidade, uma espécie de compensação, sem sucesso. A presença do filho tornou-se sofrida e triste:

\footnotetext{
E quando acontecia contemplar o filho vagando pela casa, ensimesmado, sofria mais ainda, sentindo-se responsável por aquele pequenino ser cujos mutismos e temores. Ela apenas adivinhava, mas não sabia como conjurar. Não, ela não podia viver a vida de seu filho, nem se quer ensinar-lhe a viver ela sabia. Presenciava seu jeito solitário, externado por uma autossuficiência que podia ir até a rudeza, e não possuía o dom de aproximar-se dele(...) sabia que entre ela e o filho existia uma barreira intransponível (LISPECTOR, 1976, 149).
}

A personagem principal do romance de Lispector sentia-se impotente diante do filho, não conseguia amar, pois toda a sua existência foi marcada pela morbidez, pela falta de amor e pela indisponibilidade emocional paterna e materna, que a tornou um sujeito "sem vida", impotente e isolada. Mergulha na introspecção, Marta volta a morar sozinha na cabana, sentindo-se uma mulher completamente arruinada porque "perdera a capacidade de maravilhar-se distante do encantamento dos sonhos (LISPECTOR, 1976, p.149).

Interdisciplinar, Săo Cristóvăo, UFS, v. 34, jul-dez, p. 189-206, 2020 D0I: https://doi.org/10.47250/intrell.v34i1.14976|203 


\section{Consideraçồes finais}

Os fios narrativos de $O$ muro de pedras (1976) exploram temas transversais, como melancolia e a maternidade. Através da personagem Marta percebe-se a importância da emancipação feminina, na qual há um conceito arraigado sobre a maternidade imposta pela sociedade da época. Durante muito tempo, foi considerada como um dom de todas as mulheres, uma condição do feminino. Entretanto, através das lutas feministas, reflexões sobre novas possibilidades foram inseridas nos temas de discussões teóricas, quebrando o estereótipo de ser mãe e colocando em voga o ideal de mulher. Essas novas reflexões também propiciaram a autonomia feminina diante de decisões que, até então, pareciam não ter nenhuma possibilidade de serem tomadas. Com a conscientização, a maternidade passou a ter diferentes significados, sem imposições.

A protagonista Marta, ao longo da narrativa, destoa do papel social. Com seus embates da vida, ousou sair da subjugação das regras falocêntricas em que o casamento e a maternidade estavam (e, de certa forma, ainda permanecem) inseridas. Contudo, essa tentativa de libertação em Marta foi fracassada, não por imposição da sociedade, mas pelo fato de viver fora do universo social. A personagem criou seu próprio mundo interior e individual, buscando o autoconhecimento através de uma figura feminina que questiona a vida e as dores de um "eu" melancólico.

A questão da maternidade é recorrente nos romances da autora. Em No exílio, há duas contradições sobre a maternidade. De um lado há Marin, mãe da protagonista do romance, que ocupa todo o espaço doméstico e o lugar de boa esposa, porém tinha uma doença e pouca mobilidade, deixando essa função para Lizza (protagonista da história), a qual depois de adulta faz a opção por não ter filhos, apesar de ser uma menina que cresceu sendo educada para o casamento e maternidade. $O$ fato é que Lizza vivia um grande conflito, pois, apesar de sua criação apontar para a vida familiar, ela queria conquistar um certo espaço perante a sociedade que a o espaço doméstico não permitiria.

Constância, protagonista de Ronda solitária, que no íntimo do seu ser, sentia que poderia ser mãe, predominando o instinto materno, porém, ser mãe tem influência de fatores externos

Interdisciplinar, Sầo Cristóvầo, UFS, v. 34, jul-dez, p. 189-206, 2020 D0I: https://doi.org/10.47250/intrell.v34i1.14976| 204 
à vida particular e o fato de não querer casar-se, poderia ser um obstáculo, pois ela não se adequa às normas sociais da maternidade, queria ser livre e o seu ideal de mulher não estava sincronizado com o prazer da maternidade. No livro pode-se perceber que há um abismo no qual posicionou-se a protagonista diante do fardo pesado, posto um instinto, já que ser mãe parece traduzir o esquecer-se de si mesma para o cuidado com a prole por meio do sacrifício e devoção. Constância sempre presenciava momentos de mãe com criança e isso fazia com que ela refletisse sobre a questão da maternidade, negando a aceitação das normas sociais; entendia, assim, que não poderia ser mãe.

Outra obra em que a reflexão sobre a maternidade aparece de forma latente é o $O$ dia mais longo de Thereza. Nesse romance a protagonista contesta o princípio da lógica da família sagrada libertando-se do papel social e histórico reservado para as mulheres. Neste, Thereza não ficou aprisionada ao casamento, nem à maternidade. É interessante a forma como a narradora apresenta uma relação de afabilidade e delicadeza ao se referir à família de Thereza: "no geral, porém, era ameno e perfeito na sua trindade: pai, mãe e filha" (LISPECTOR, 1965, p. 23), evocando a Trindade Pai, Filho e Espírito, ou seja, há uma rasura da tradição cristã.

Como a obra sugere, durante toda a vida, Thereza se sentiu insegura e frágil. Por esse motivo não quis procriar: "filhos, não os tivera. Não. Jamais se espantara em não tê-los tido, de tal forma sempre lhe parecera estar vicejando como uma árvore duramente podada, sem possibilidade de floração" (LISPECTOR, 1965, p. 91). Ter um filho significaria um investimento emocional, afetivo, educacional, pensar no futuro. Entretanto, ela sempre dizia a si mesma: "o essencial é caminhar com os meus próprios pés, abrir meu caminho, ser eu mesma, sem interferência de ninguém" (LISPECTOR, 1965, p. 28).

Dessa forma, as relações e as análises aqui apresentadas demonstram que a luta pela desmitificação da mulher e do papel colocado na maternidade está cada vez mais frágil, especialmente pelo fato de que as mulheres continuam buscando um lugar de escolha, independente daquilo que a sociedade ou os costumes sociais e religiosos tendem a reforçar no discurso falocêntrico. Toda forma de decisão sobre o papel que se quer representar e/ ou a decisão pela opção da maternidade, tornou-se cada vez mais D0I: https://doi.org/10.47250/intrell.v34i1.14976| 205 
discutivel e opcional e assim, a personagem Marta, bem como as demais personagens citadas nesse estudo, se prestou de maneira bastante pertinente ao papel de análise para esse artigo e trouxe uma nova possibilidade de reflexão diante dessa condição contemporânea tão subvertida.

\section{Referências}

BADINTER, Elisabeth. Um amor conquistado: o mito do amor materno - Tradução de Waltensir Dutra. - Rio de Janeiro: Nova Fronteira, 1985.

GOTLIB, N. B. Por uma nova história das mulheres escritoras no Brasil: algumas anotações em torno das irmãs Lispector. In: ZINANI, Cecil Jeanine Albert; SANTOS, Salete Rosa Pezzi dos (Org.). Trajetórias de literatura e gênero: territórios reinventados. Caxias do Sul: EDUCS, 2016.

FERRUA, Pietro. Indagações metafísicas na obra de Elisa Lispector. In: LISPECTOR, Elisa. O dia mais longo de Thereza. 2.ed. Rio de Janeiro: Rocco, 1978.

GREEN, A. Narcisismo de vida, narcisismo de morte. Trad. Claudia Berliner. São Paulo, Escuta, 1980.

HENRIQUE. J.K.B. A perspectiva narrativa em amor, de Elisa Lispector. In: VI ENLIJE -Encontro Nacional de Literatura Infanto-Juvenil e Ensino, Campina Grande, 2016.

SENNA, Homero. [Orelha do livro]. Rio de Janeiro: editora Rocco, 1976.

LAURETIS, T. Tecnologias do gênero. In: Hollanda, H.B. (orga.) Tendências e impasses: o feminismo como crítica da cultura. Rio de Janeiro: Rocco, 1994.

LISPECTOR, Elisa. O muro de pedras. Rio de Janeiro: editora do Rocco, 1976.

MASSON, Jeferson Alves. Elisa Lispector: registros de um encontro. 2015. Dissertação (mestrado) - Pontifícia Universidade Católica do Rio de Janeiro, Departamento de Letras, 2015.

SILVA, Patrícia Lopes da. Exílio e deslocamento feminino: a literatura nômade de Elisa Lispector - Tese de Doutorado, UFU, 2020. Disponível em: https://repositorio.ufu.br/handle/123456789/30475.

WALDMAN, Berta. Clarice e Elisa Lispector: caminhos divergentes. Webmosaica. v. 6, n. 1, Jan.-Jun., 2014. Disponível em: Acesso em: 10 março de 2017.

Interdisciplinar, Săo Cristóvăo, UFS, v. 34, jul-dez, p. 189-206, 2020 DOI: https://doi.org/10.47250/intrell.v34i1.14976| 206 